\title{
Synthesis of Factor VIII Antigen by Cultured Guinea Pig Megakaryocytes
}

\author{
Ralph Nachman, Richard Levine, and Eric A. JafFe, Department of \\ Medicine, Cornell University Medical College, New York 10021 and \\ the Rockefeller University, New York 10021
}

A B S T R A C T Immunoprecipitates containing guinea pig Factor VIII antigen were prepared from guinea pig plasma with a cross-reacting rabbit anti-human Factor VIII. Monospecific antisera to guinea pig Factor VIII antigen were produced in rabbits by using these washed immunoprecipitates as immunogens. The resulting antisera to guinea pig Factor VIII antigen detected Factor VIII antigen in guinea pig plasma and inhibited the von Willebrand factor activity in guinea pig plasma. This antibody also detected Factor VIII antigen in a solubilized protein mixture prepared from isolated cultured guinea pig megakaryocytes. Cultured guinea pig megakaryocytes were labeled with radioactive leucine. By radioautography, $96.2 \%$ of the radioactivity was present in megakaryocytes. The radioactive Factor VIII antigen present in the solubilized cell protein mixture was isolated by immunoprecipitation and characterized by sodium dodecyl sulfate polyacrylamide gel electrophoresis. The results demonstrate that cultured guinea pig megakaryocytes synthesize Factor VIII antigen which contains the same polypeptide subunit (mol wt 200,000 ) present in guinea pig plasma Factor VIII antigen.

\section{INTRODUCTION}

Immunofluorescence studies performed on a variety of human tissue sections with a monospecific rabbit antihuman Factor VIII have demonstrated that, in vivo, only endothelial cells, platelets, and megakaryocytes contain Factor VIII antigen (VIII:AGN) ${ }^{1}(1,2)$. We have

Dr. Levine's present address is Veterans Administration Hospital, Washington, D. C. 20422. Dr. Jaffe is the recipient of Research Career Development Award 1 K04 HL 00237 from the National Institutes of Health and a Career Scientist Award from the Irma T. Hirschl Trust.

Received for publication 2 December 1976 and in revised form 3 June 1977.

${ }^{1}$ Abbreviations used in this paper: DTT, dithiothreitol; VIII:AGN, Factor VIII antigen; VIII:AHF, Factor VIII procoagulant activity; VIII:VWF, von Willebrand factor; MEM, minimal essential medium; PBS, phosphate-buffered saline; SDS, sodium dodecyl sulfate. previously demonstrated that cultured human endothelial cells synthesize and release a protein(s) which has VIII:AGN and von Willebrand factor (VIII:VWF) $(3,4)$. We have also demonstrated the presence of VIII:AGN and VIII:VWF in subcellular platelet membrane and granule fractions (5). The VIII:AGN present in the membrane and granule fractions of human platelets has the same subunit structure as the VIII:AGN in human plasma (5). Thus, the platelet contains two anatomically separate pools of VIII:AGN and VIII:VWF; one is associated with intracellular granules and the other is associated with the external membrane surface.

The VIII:AGN and VIII:VWF in the surface membrane pool most likely is derived from circulating plasma VIII:AGN and VIII:VWF (6). The origin of the VIII:AGN and VIII:VWF in the intracellular granule pool is unknown. Proteins such as VIII:AGN probably do not cross cell membranes and therefore it is unlikely that intracellular granule VIII:AGN is derived from plasma. Platelets and megakaryocytes in patients with severe von Willebrand's disease do not contain intracellular VIII:AGN (7-12) and do not acquire the protein after transfusion $(7,10,11)$. These observations suggest that exogenous plasma VIII:AGN does not gain access to the platelet's interior and suggests that megakaryocytes and (or) platelets synthesize the VIII:AGN and VIII:VWF present in the granule pool. Platelets have no DNA and only a vestigial protein synthetic apparatus; however, megakaryocytes synthesize platelet protein (13).

Recently, one of us (R. L.) has developed techniques for the isolation and culture of guinea pig megakaryocytes $(14,15)$. In this paper, we show that cultured guinea pig megakaryocytes synthesize VIII:AGN which has the same antigenic determinants and subunit molecular weight as guinea pig plasma VIII:AGN.

\section{METHODS}

Harvesting, concentration, and in vitro culture of megakaryocytes. The techniques of isolating and culturing megakaryocytes have been described elsewhere $(14,15)$. Femoral 
marrow from four guinea pigs at a time was disaggregated in calcium- and magnesium-free Hanks' solution containing citrate, adenosine, and theophylline. The marrow cell suspension was subjected to density equilibrium centrifugation on a discontinuous albumin gradient with specific gravities of 1.035-1.050. The cells of specific gravity $<1.050$ were enriched in megakaryocytes. This population was subjected to two successive velocity sedimentations at unit gravity. The larger, faster sedimenting cells were mostly megakaryocytes. To quantitate the relative cell volumes, 250 megakaryocytes and 250 contaminating cells from each of four separate isolations were sized after the second velocity sedimentation, and after $20 \mathrm{~h}$ in culture, by methods described previously (14).

The isolated cell population was suspended in Dulbecco's minimal essential medium (MEM) containing $10 \%$ (vol/vol) heat-inactivated, pooled guinea pig serum (Grand Island Biological Co., Grand Island, N. Y.) and 2.3\% (wt/vol) bovine albumin (Armour Pharmaceutical Co., Chicago, Ill.). The suspension of megakaryocytes was cultured in glass vials in $5 \% \mathrm{CO}_{2}$ at $37^{\circ} \mathrm{C}$ for $20 \mathrm{~h}$.

Determination of megakaryocyte population purity. Megakaryocytes and contaminating cells were counted in hemocytometers (14). In four different experiments mean cell diameters were determined with an optical micrometer (14) after isolation and again after overnight culture. At least 250 megakaryocytes and 250 non-megakaryocytes were measured at each point in each experiment. Cultured cell suspensions were examined by phase contrast and bright-field microscopy (14) to confirm the nature of the contaminating cell types. To exclude the presence of adherent endothelial cells in the cultures, cover slips placed into vials (15) were examined at the ends of the incubation periods. Immunofluorescence studies were performed with the rabbit antibody against guinea pig VIII-AGN (vide infra) followed by fluoresceinated goat anti-rabbit IgG on cultured cell populations spun onto glass coverslips as described $(3,14)$.

Megakaryocyte solubilization. In general, studies were performed on the isolated cultured megakaryocytes obtained from the femurs of 12-16 guinea pigs. At the end of the incubations, the cells were harvested by aspirating the contents of the vials. The cells were washed three times with calciumand magnesium-free Hanks' solution and promptly frozen and stored at $-70^{\circ} \mathrm{C}$. The cell buttons were thawed and extracted for $18 \mathrm{~h}$ at $4^{\circ} \mathrm{C}$ with $0.3-0.5 \mathrm{ml}$ of phosphate-buffered saline (PBS, $0.154 \mathrm{M} \mathrm{NaCl}, 0.01 \mathrm{M}$ phosphate, $\mathrm{pH}$ 7.4) containing $0.1 \%$ Lubrol PX (Sigma Chemical Co., St. Louis, Mo.), $0.4 \mathrm{mM}$ N-CBZ- $\alpha$-L-glutamyl-L-tyrosine, $250 \mu \mathrm{g} / \mathrm{ml}$ soybean trypsin inhibitor (Worthington Biochemical Corp., Freehold, N. J.), $0.5 \mathrm{mM}$ phenyl methyl sulfonyl fluoride (Sigma Chemical Co.), and Trasylol, $100 \mathrm{U} / \mathrm{ml}$ (FBA Pharmaceuticals, Inc., New York). The solubilized megakaryocyte protein was separated from insoluble material by ultracentrifugation at $100,000 \mathrm{~g}$ for $1 \mathrm{~h}$ at $4^{\circ} \mathrm{C}$. Lubrol PX solubilized between 52 and $64 \%$ of the total megakaryocyte protein.

Guinea pig platelets. Guinea pig blood was drawn by cardiac puncture into plastic syringes containing $1 / 10 \mathrm{vol}$ of $3.8 \%$ sodium citrate. The anticoagulated blood was diluted with an equal volume of calcium- and magnesium-free Hanks' solution and centrifuged at $250 \mathrm{~g}$ for $15 \mathrm{~min}$ at $20^{\circ} \mathrm{C}$. The diluted platelet rich plasma was aspirated and the platelets harvested by centrifugation at $1,500 \mathrm{~g}$ for $20 \mathrm{~min}$. The platelets were washed with calcium-magnesium-free Hanks' solution.

Semipurified guinea pig VIII:AGN. This was prepared from citrated guinea pig plasma stored frozen at $-70^{\circ} \mathrm{C}$. The guinea pig plasma was thawed and placed in a $2^{\circ} \mathrm{C}$ water bath, and $95 \%$ ethanol was added slowly to a final concentration of $8 \%$. The temperature was lowered to $-2^{\circ} \mathrm{C}$ and the plasma was incubated for $15 \mathrm{~min}$. The precipitate was collected by centrifugation at $25,000 \mathrm{~g}$ for $20 \mathrm{~min}$ at $-2^{\circ} \mathrm{C}$. The precipitate was redissolved in $1 / 10$ the original volume in PBS containing $1 \mathrm{mM}$ EDTA, $0.02 \%$ sodium azide, and Trasylol, $100 \mathrm{U} / \mathrm{ml}$. The redissolved precipitate was absorbed with $1 / 10 \mathrm{vol}$ of aluminum hydroxide gel (Gallard-Schlesinger Chemical Mfg. Corp., Carle Place, N. Y.) for $10 \mathrm{~min}$ at $37^{\circ} \mathrm{C}$ and the aluminum hydroxide gel removed by centrifugation at $39,000 \mathrm{~g}$ for $20 \mathrm{~min}$ at $20^{\circ} \mathrm{C}$. The redissolved precipitate was then chromatographed on a $2.5 \times 90$-cm column of Sepharose $4 \mathrm{~B}$ (Pharmacia Fine Chemicals, Inc., Piscataway, N. J.), at a flow rate of $3 \mathrm{ml} / \mathrm{cm}^{2}$ per h with PBS containing $1 \mathrm{mM}$ EDTA and $0.02 \%$ sodium azide. 4.4-ml fractions were collected in polypropylene tubes. The void volume peak was concentrated to 0.36 $\mathrm{mg} / \mathrm{ml}$ with a ProDiCon concentrator (Bio-Molecular Dynamics, Beaverton, Ore.), and the resulting concentrate used as semipurified guinea pig plasma VIII:AGN. This material, when analyzed by sodium dodecyl sulfate (SDS)-polyacrylamide gel electrophoresis after reduction with dithiothreitol (DTT), contained three major and two minor bands. One of the major bands migrated with mol wt of 200,000 . Purified human plasma VIII:AGN was prepared as previously described (16).

Antisera. Monospecific rabbit anti-human Factor VIII was obtained from Behring Diagnostics, American Hoechst Corp., Somerville, N. J. This antibody precipitates VIII:AGN, inhibits Factor VIII procoagulant activity (VIII:AHF) of normal plasma, and inhibits ristocetin-induced platelet aggregation (VIII:VWF). By immunodiffusion, this antibody reacted with a single line of identity when tested against normal plasma, hemophilic plasma, and human Factor VIII concentrate (Hemofil, Hyland Div., Travenol Laboratories, Inc., Costa Mesa, Calif.). The antibody did not react with cold insoluble globulin as shown by the fact that it did not form a precipitin line with plasma from patients with severe von Willebrand's disease.

The rabbit anti-human Factor VIII was used to purify guinea pig VIII:AGN which in turn was used as an immunogen. The rabbit anti-human Factor VIII appeared to form a line of partial identity when reacted against human plasma and guinea pig plasma (Fig. 1). An antigen identical to that in guinea pig plasma was detected in the semipurified guinea pig VIII:AGN. The rabbit anti-human Factor VIII was allowed to diffuse against the partially purified guinea pig plasma VIII:AGN in $1 \%$ agarose at room temperature for $72 \mathrm{~h}$. The slides were washed for $96 \mathrm{~h}$ at room temperature in PBS with multiple changes and the immunoprecipitin lines cut out with a razor blade. Material from 12 sets of immunodiffusion lines were pooled, lyophilized, and homogenized in an equal volume of $0.15 \mathrm{M} \mathrm{NaCl}$ and complete Freund's adjuvant with a 25-gauge needle and tuberculin syringe. The suspension $(0.6 \mathrm{ml})$ was

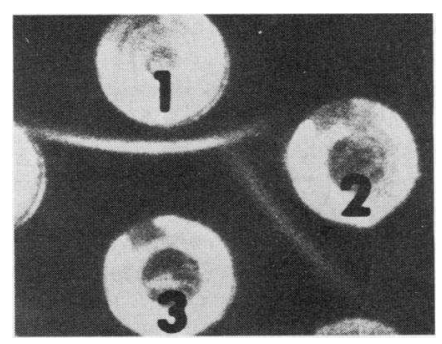

FIGURE 1 Cross reactivity of guinea pig VIII:AGN and human VIII:AGN. Immunodiffusion analysis of human plasma (1) and guinea pig plasma (2) reacted against anti-human VIII:AGN (3). 
injected into multiple intradermal sites on the shaved back of a New Zealand albino rabbit. The animal was reimmunized with washed immunoprecipitate on days $26,56,100$, and 124 . Antiserum obtained on day 144 was used for these studies.

Rabbit antiserum to guinea pig fibrinogen was produced in a manner identical to that used for guinea pig VIII. Immunoprecipitates obtained by reacting rabbit anti-human fibrinogen with guinea pig plasma were used to immunize rabbits. The antiserum elicited in rabbits was monospecific for guinea pig fibrinogen. ${ }^{2}$

Anticeruloplasmin and purified human ceruloplasmin were obtained from Behring Diagnostics. Antisera were absorbed once with $1 / 10 \mathrm{vol} \mathrm{Al}(\mathrm{OH})_{3}$ gel and heated to $56^{\circ} \mathrm{C}$ for $30 \mathrm{~min}$ to remove residual coagulant proteins.

Protein synthesis of cultured megakaryocytes. $\quad\left[{ }^{3} \mathrm{H}\right] \mathrm{Leu}-$ cine or $\left[{ }^{3} \mathrm{H}\right]$ amino acid incorporation into TCA-precipitable material was used as an index of protein synthesis. To study protein synthesis as a function of time, 700,000 cultured guinea pig megakaryocytes were incubated in MEM containing $10 \%$ guinea pig serum, $2.3 \%$ bovine serum albumin, and $7 \mu \mathrm{Ci} / \mathrm{ml}$ of an $\mathrm{L}\left[{ }^{3} \mathrm{H}\right]$ amino acid mixture (New England Nuclear, Boston, Mass.). After the appropriate labeling period, the medium containing the megakaryocytes was removed and the megakaryocytes harvested by centrifugation at $250 \mathrm{~g}$ for $8 \mathrm{~min}$ at $20^{\circ} \mathrm{C}$. The megakaryocytes were washed three times by resuspension and centrifugation with cold calciumand magnesium-free Hanks' solution containing an amino mixture at $0.1 \mathrm{mM}$ (same composition as the $\left[{ }^{3} \mathrm{H}\right]$ amino acid mxiture) and then three times with $10 \%$ TCA containing the 0.1-mM amino acid mixture. The megakaryocyte cell pellet was dissolved in $1 \mathrm{ml}$ of a solution containing $2 \%$ SDS-8.5 M urea-14 mM DTT by boiling for $3 \mathrm{~min}$. $200 \mu \mathrm{l}$ of the solution was added to $10 \mathrm{ml}$ PCS liquid scintillation cocktail (Amersham/Searle Corp., Arlington Heights, Ill.) and counted in a Searle Mark III liquid scintillation spectrometer. Counting efficiency was determined with an external standardization procedure.

To study the effect of $\left[{ }^{3} \mathrm{H}\right]$ leucine concentration on incorporation of radioactivity into TCA-precipitable protein, megakaryocytes were cultured in leucine-free MEM containing $10 \%$ guinea pig serum, $2.3 \%$ bovine serum albumin, and varying amounts of $\mathrm{L}(4,5)\left[{ }^{3} \mathrm{H}\right]$ leucine, sp act $60 \mathrm{Ci} / \mathrm{mmol}(\mathrm{New}$ England Nuclear), for $20 \mathrm{~h}$. The labeled megakaryocytes were processed and counted as above, except that the calcium- and magnesium-free Hanks' solution and the $10 \%$ TCA used to wash the cells contained $0.1 \mathrm{mM}$ leucine instead of $0.1 \mathrm{mM}$ amino acids.

For studies with cycloheximide (Sigma Chemical Co.), cultured megakaryocytes were incubated for $15 \mathrm{~min}$ with cycloheximide before incubation for $8 \mathrm{~h}$ with $\left[{ }^{3} \mathrm{H}\right]$ leucine, $5 \mu \mathrm{Ci} / \mathrm{ml}$, in leucine-free MEM containing varying amounts of cycloheximide.

For immunologic and functional studies of labeled megakaryocyte protein, megakaryocytes were cultured for $20 \mathrm{~h}$ in leucine-free MEM containing $\left[{ }^{3} \mathrm{H}\right.$ ]leucine, 10 $\mu \mathrm{Ci} / \mathrm{ml}$, and washed three times in calcium- and magnesiumfree Hank's solution containing $0.1 \mathrm{mM}$ leucine and solubilized in Lubrol as above.

Pronase digestion of TCA-precipitable material synthesized by megakaryocytes. Cultured megakaryocytes in leucine-free MEM containing 5\% guinea pig serum and $2.3 \%$ bovine serum albumin were labeled with $\left[{ }^{3} \mathrm{H}\right]$ leucine, $3.3 \mu \mathrm{Ci} / \mathrm{ml}$, for $18 \mathrm{~h}$. The megakaryocytes were washed three times with calcium- and magnesium-free Hanks' solution containing $0.1 \mathrm{mM}$ leucine by centrifugation at $250 \mathrm{~g}$

\footnotetext{
${ }^{2}$ Nachman, R., R. Levine, and E. Jaffe. Manuscript in preparation.
}

for $8 \mathrm{~min}$ at $20^{\circ} \mathrm{C}$, then incubated in cold $10 \%$ TCA containing $0.1 \mathrm{mM}$ leucine for $10 \mathrm{~min}$, and washed three times by centrifugation in the same solution. The megakaryocytes were dissolved in $1 \mathrm{ml}$ of $1 \mathrm{~N} \mathrm{NaOH}$. Solubilized samples were neutralized with $6 \mathrm{~N} \mathrm{HCl}$, and dialyzed exhaustively against $10 \mathrm{mM}$ Tris, $\mathrm{pH}$ 7.8. The samples were digested for $48 \mathrm{~h}$ at $37^{\circ} \mathrm{C}$ with pronase $(0.5 \mathrm{mg} / \mathrm{ml}$, Calbiochem, San Diego, Calif.). At the end of the digestion, carrier bovine serum albumin was added $(1 \mathrm{mg} / \mathrm{ml}$, final concentration) followed by enough $50 \%$ TCA to make the solution $10 \%$ in TCA and the samples were incubated overnight at $4^{\circ} \mathrm{C}$. The precipitates were removed by centrifugation, washed once with $10 \%$ TCA, and dissolved in $200 \mu \mathrm{l}$ of $2 \%$ SDS-8.5 M urea-14 mM DTT by boiling for $3 \mathrm{~min}$. A sample of this was counted as above. Control experiments were run by omitting the pronase. The results are expressed as a percentage of the control value.

Radioautography of cultured megakaryocyte populations. Purified megakaryocyte populations were incubated overnight with $\left[{ }^{3} \mathrm{H}\right]$ leucine, as above. The cells were washed three times in calcium- and magnesium-free Hanks' solution containing $0.1 \mathrm{mM}$ leucine and then fixed as for electron microscopy (14). Epon sections (Shell Chemical Co., Houston, Tex.) $1 \mu \mathrm{m}$ thick were cut on a Porter-Blum MT-2 ultramicrotome (DuPont Instruments, Sorvall Operations, Newtown, Conn.), dried, and dipped into Ilford L4 emulsion melted in a water bath. The slides were dried and kept in the dark for $19 \mathrm{~h}$ to 4 days. The autoradiographs were developed in Microdol-X, stained lightly with azure Blue, and examined by bright-field microscopy at a magnification of 2,000 . Grains were counted over 96 megakaryocytes and 64 non-megakaryocytes on a single section exposed for $19 \mathrm{~h}$.

$\gamma$-Globulin fractions. These were prepared as previously described (5).

Quantitative immunoelectrophoresis of VIII:AGN. This was carried out as described previously (5).

SDS polyacrylamide gel electrophoresis. SDS-polyacrylamide gel electrophoresis (5\% gels) was performed according to the method of Weber and Osborn, as previously described $(5,17)$. Samples for analysis were added to an equal volume of a solution containing $8.5 \mathrm{M}$ urea, 2\% SDS, and $14 \mathrm{mM}$ DTT, and boiled for $5 \mathrm{~min}$. Precipitin bands in agar were cut out, heated sufficiently in a water bath to melt the agar, and prepared for gel electrophoresis by solubilization in $100 \mu \mathrm{l}$ of $8.5 \mathrm{M}$ urea, $2 \%$ SDS, $14 \mathrm{mM}$ DTT, and boiled before application on the gel. For some studies, the reducing agent DTT was omitted. Radioactivity labeling patterns were determined by slicing the gels (2$\mathrm{mm}$ slices) and assaying the radioactivity of the individual slices as previously described (17). The molecular weight of VIII:AGN was determined by SDS acrylamide gel electrophoresis as described $(5,16)$.

Anti-VIII:AHF assay. The inhibition of VIII:AHF in guinea pig plasma by rabbit anti-guinea pig VIII:AGN was assayed after equal volumes of antibody and plasma were incubated for $2 \mathrm{~h}$ at $37^{\circ} \mathrm{C}$. The mixture was assayed for VIII:AHF by a one-stage method with VIII:AHFdeficient human plasma (18). VIII:AHF was assayed in the megakaryocyte protein solution with this same humandeficient system.

Anti-VIII:VWF assay. The inhibition of VIII:VWF in guinea pig plasma by rabbit anti-guinea pig VIII:AGN was assayed with formalin-fixed washed normal human platelets (19). The assay system included normal guinea pig plasma as a source of VIII:VWF, the rabbit antiserum, and ristocetin (Abbott Laboratories, Chemical Div., North Chicago, Ill.). Aggregation studies were performed 
with a Payton aggregation module (Payton Associates, Buffalo, N. Y.). In these experiments, the sensitivity of the recording was increased by setting $100 \%$ transmission with a dilute platelet suspension (one-half the concentration of the test platelet suspension) rather than with buffer.

\section{RESULTS}

Megakaryocyte cultures. The average yield in a single experiment from four guinea pigs was 719,000 megakaryocytes $\pm 53,900$ (mean $\pm S E M, n=20)$. The megakaryocytes comprised $64.5 \pm 2.6 \%$ (mean $\pm \mathrm{SEM}$, $\mathrm{n}=20$ ) of the freshly isolated total cell populations. The megakaryocytes were much larger than the contaminating cells (mean volumes 15,000 and 420 $\mu \mathrm{m}^{3}$, respectively), so that the megakaryocyte cell mass comprised $98.5 \%$ of the total. After $20 \mathrm{~h}$ in culture the megakaryocytes comprised $44.7 \pm 8.5 \%$ (mean $\pm \mathrm{SEM}, n=20$ ) of the cell population by number and $96.1 \%$ of the cell mass. No endothelial cells were seen either in the cell suspensions after culture or on cover slips retrieved from the bottoms of the culture vials. Immunofluorescence studies performed on cover slip preparations of cultured cells revealed that Factor VIII:AGN was not detectable in the contaminating erythroid, myeloid, or mononuclear cells but was present in the megakaryocytes.

Guinea pig megakaryocyte and platelet proteins. There were striking similarities in the SDS polyacrylamide gel patterns of the solubilized proteins obtained from isolated cultured guinea pig megakaryocytes and isolated guinea pig platelets (Fig. 2). A

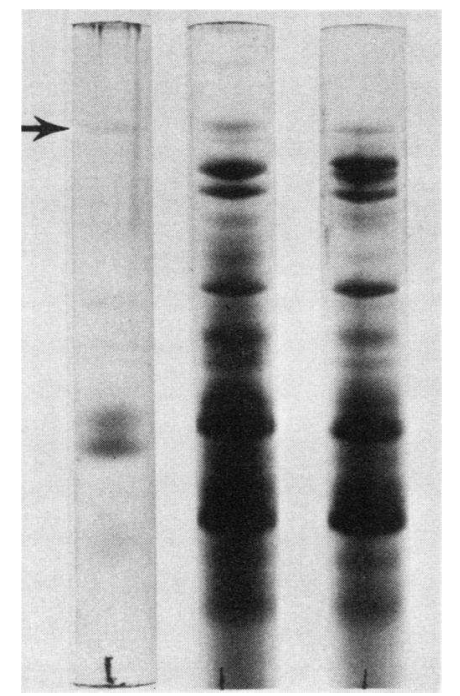

FIGURE 2 Similarity of guinea pig megakaryocyte and guinea pig platelet proteins. SDS acrylamide gels of semipurified guinea pig VIII:AGN (left), isolated washed megakaryocytes (center) and washed guinea pig platelets (right). Arrow indicates 200,000 -mol wt band which moves in position of VIII:AGN. polypeptide of mol wt 200,000 (arrow) was present in both preparations. This polypeptide moved in the same area of the gel as human plasma VIII:AGN and guinea pig plasma VIII:AGN markers.

Specificity of the rabbit anti-guinea pig VIII:AGN. The immunoprecipitate formed by reacting rabbit anti-human Factor VIII and guinea pig VIII:AGN was used as an immunogen. When the resulting rabbit antibody to guinea pig VIII:AGN was reacted against guinea pig plasma and guinea pig VIII:AGN, a single line of identity was formed (Fig. 3).

To clarify the specificity of the rabbit anti-guinea pig VIII:AGN, studies were performed to characterize the molecular subunit structure of the antigen precipitated by the antibody. In addition, the antibody's specificity was compared to the known specificity of the rabbit anti-human VIII:AGN. For these studies, immunoprecipitates were formed in agar plates between the respective antibodies and guinea pig plasma. The precipitates were washed, cut out, and analyzed on SDS acrylamide gels. The protein precipitated from guinea pig plasma by the rabbit anti-guinea pig VIII:AGN had the same subunit polypeptide mol wt $(200,000)$ on SDS gels as the protein precipitated from guinea pig plasma by the cross-reacting monospecific rabbit anti-human VIII (Fig. 4). The protein peaks in the 50,000 - and 25,000 -mol wt regions represent the $\mathrm{H}$ and $\mathrm{L}$ chains of the antibodies. The gel pattern for the reduced antibody alone revealed only $\mathrm{H}$ and $\mathrm{L}$ chains. These studies were performed in the presence of DTT. In the absence of the reducing agent, only intact $\gamma$-globulin entered the gel. This moved with an apparent mol wt of approximately 100,000 and was identified by comparison with a known IgG marker. These studies demonstrate the VIII:AGN specificity of the rabbit anti-guinea pig VIII:AGN.

The antiserum to guinea pig VIII:AGN did not react with unconcentrated human plasma but did form a faint precipitin with purified human VIII:AGN. The antiserum inhibited the VIII:VWF activity of guinea pig plasma when it was assayed with para-

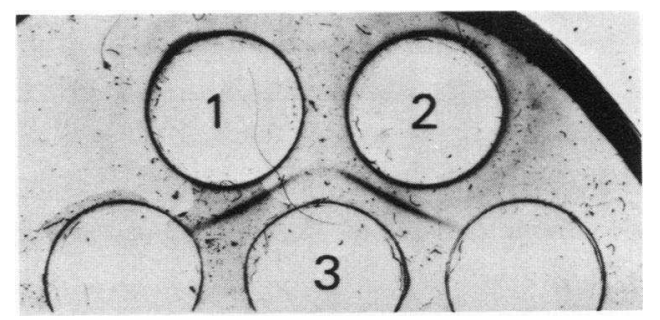

FIGURE 3 Immunodiffusion analysis of the rabbit antiserum to guinea pig VIII:AGN. Guinea pig plasma (1) and semipurified guinea pig VIII:AGN (2) were reacted against rabbit anti-guinea pig VIII:AGN (3). 


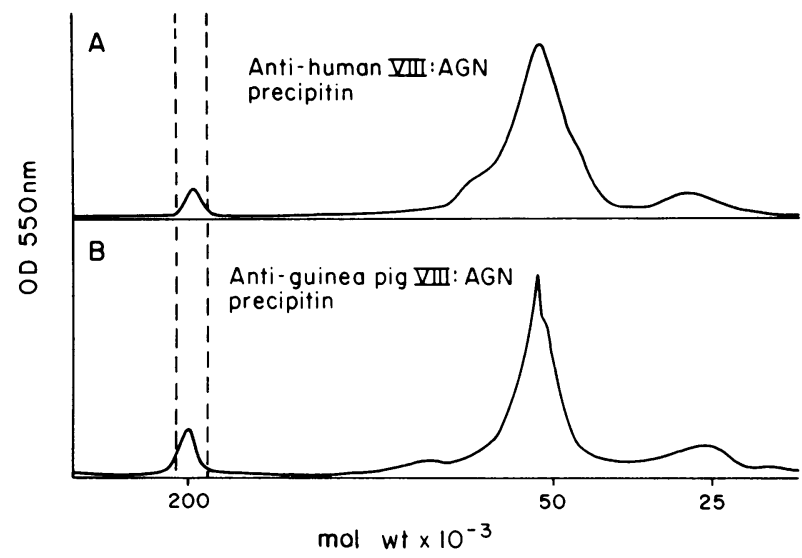

FIGURE 4 Specificity of anti-guinea pig VIII:AGN. Densitometric scans of SDS polyacrylamide gels of washed immunoprecipitin lines formed between guinea pig plasma and (A) rabbit anti-human VIII:AGN and (B) rabbit antiguinea pig VIII:AGN. The vertical dashed lines enclose the guinea pig plasma VIII:AGN subunit region.

formaldehyde-fixed washed human platelets (Fig. 5). A control antiserum, rabbit anti-guinea pig fibrinogen, had no inhibitory effect. The rabbit anti-guinea pig VIII:AGN did not inhibit the VIII:AHF in normal guinea pig plasma.

VIII:AGN in solubilized megakaryocytes. The rabbit anti-guinea pig VIII:AGN precipitated an antigen in the megakaryocyte protein solution which was similar or identical to an antigen in semipurified guinea pig plasma VIII:AGN (Fig. 6). By quantitative immunoelectrophoresis, the megakaryo-

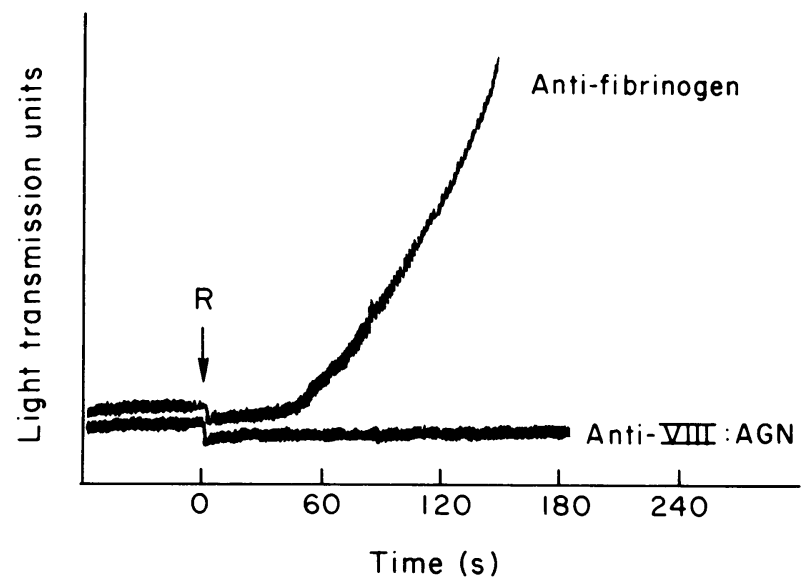

FIGURE 5 Inhibition of ristocetin-induced platelet aggregation by the anti-guinea pig VIII:AGN. $0.4 \mathrm{ml}$ of paraformaldehyde-fixed washed platelets $(120,000 / \mu \mathrm{l}$ in PBS) were incubated with $50 \mu \mathrm{l}$ of normal guinea pig plasma and with $50 \mu$ l of a 1:5 dilution in PBS of rabbit antiguinea pig VIII:AGN followed by ristocetin (R), $50 \mu \mathrm{l}$, to a final concentration of $0.8 \mathrm{mg} / \mathrm{ml}$. A control experiment was performed with rabbit anti-guinea pig fibrinogen.

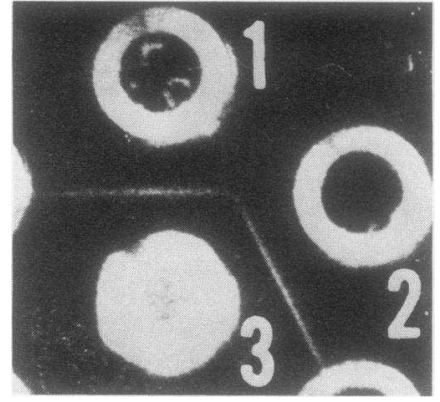

FIgURE 6 Guinea pig VIII:AGN in megakaryocyte protein solution. Immunodiffusion analysis of megakaryocyte protein solution (1) and semipurified guinea pig plasma VIII:AGN (2) reacted against anti-guinea pig VIII:AGN (3).

cyte protein solution contained $0.8 \mathrm{U}$ of VIII:AGN $/ \mathrm{mg}$ of protein (mean of four separate experiments). The VIII:AGN in the megakaryocyte protein solution reacted identically to the guinea pig plasma VIII:AGN standard in quantitative immunoelectrophoresis. When the heights of the rocket precipitins obtained from serial dilutions of the megakaryocyte protein solution and the plasma standard were graphically plotted, the two lines connecting the two different sets of points were parallel.

Megakaryocyte protein synthesis. Megakaryocytes incubated with $\left[{ }^{3} \mathrm{H}\right]$ amino acids or $\left[{ }^{3} \mathrm{H}\right]$ leucine at $37^{\circ} \mathrm{C}$ incorporated radioactivity into TCA-precipitable material. Incorporation varied linearly with time (Fig. 7A) and with $\left[{ }^{3} \mathrm{H}\right]$ leucine concentration (Fig. 7B). To establish that the radioactivity in the TCA-precipitable material was incorporated into protein, the material was digested with the proteolytic enzyme pronase. Digestion with pronase reduced the TCA-precipitable radioactivity in megakaryocyte pro-
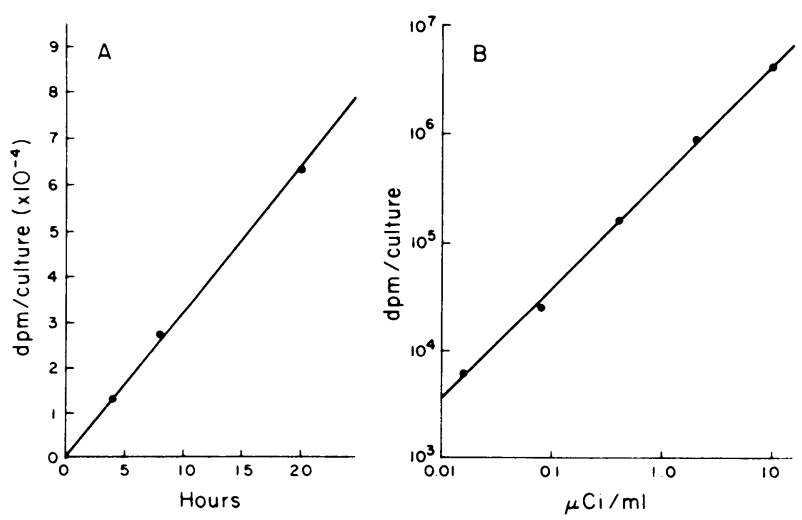

FIgure 7 Synthesis of megakaryocyte proteins. (A) Timedependent incorporation of $\left[{ }^{3} \mathrm{H}\right]$ leucine $(5 \mu \mathrm{Ci} / \mathrm{ml})$ into protein by cultured guinea pig megakaryocytes. (B) Dosedependent incorporation of $\left[{ }^{3} \mathrm{H}\right]$ leucine into protein by cultured guinea pig megakaryocytes incubated for $17 \mathrm{~h}$. 
tein by $96 \%$. Cycloheximide at $5 \mu \mathrm{g} / \mathrm{ml}$ suppressed protein synthesis by $95 \%$.

Radioautography of $1-\mu \mathrm{m}$ sections of Epon-embedded, $\left[{ }^{3} \mathrm{H}\right]$ leucine-labeled cells revealed that practically all cell-associated grains were present over the megakaryocytes (Fig. 8). The mean grain count was 59.4 per megakaryocyte section but only 5.92 per section of non-megakaryocytes. With corrections for nonequatorial sections (20) and cell volumes determined in separate experiments, the mean grain count was calculated to be 638 for whole megakaryocytes and 20.4 for the contaminating cells. Since it was determined that megakaryocytes comprised $44.7 \%$ of the cell populations after overnight culture, the megakaryocyte-associated grains comprised $96.2 \%$ of all cell-associated grains. This figure corresponds closely to the megakaryocyte fraction of the total cell mass in these populations.

Immunoprecipitation of VIII:AGN synthesized by cultured guinea pig megakaryocytes. For these studies, the immunoprecipitate formed in agar between solubilized megakaryocyte protein obtained from $\left[{ }^{3} \mathrm{H}\right]$ leucine-labeled cells and rabbit anti-guinea pig VIII:AGN was washed in PBS for 5 days, cut out, and analyzed on SDS acrylamide gels. The protein pattern of partially purified guinea pig plasma VIII:AGN used as a marker is shown in Fig. 9A. The radioelectrophorogram obtained after SDS gel

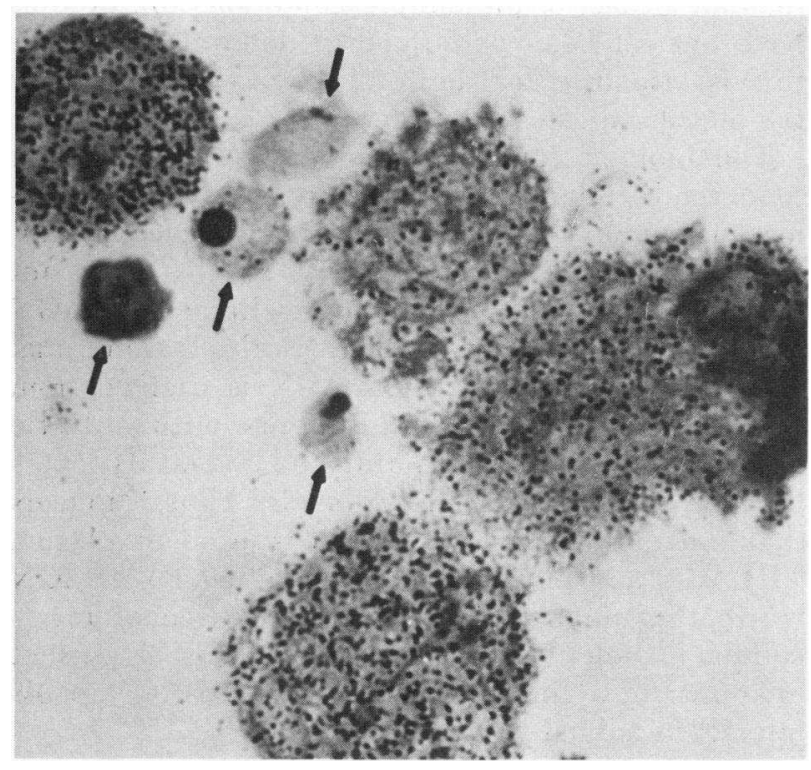

FIGURE 8 Radioautography of megakaryocyte culture. Autoradiographs of a $1-\mu \mathrm{m}$ section of a megakaryocyte population incubated for $18 \mathrm{~h}$ with $\left[{ }^{3} \mathrm{H}\right]$ leucine and exposed 4 days. Four megakaryocytes (larger cells) have many overlying grains. In contrast, other cell types (arrows: 2 erythroblasts, 1 erythrocyte, 1 lymphocyte) showed only a few grains. Magnification $\times 1,900$.

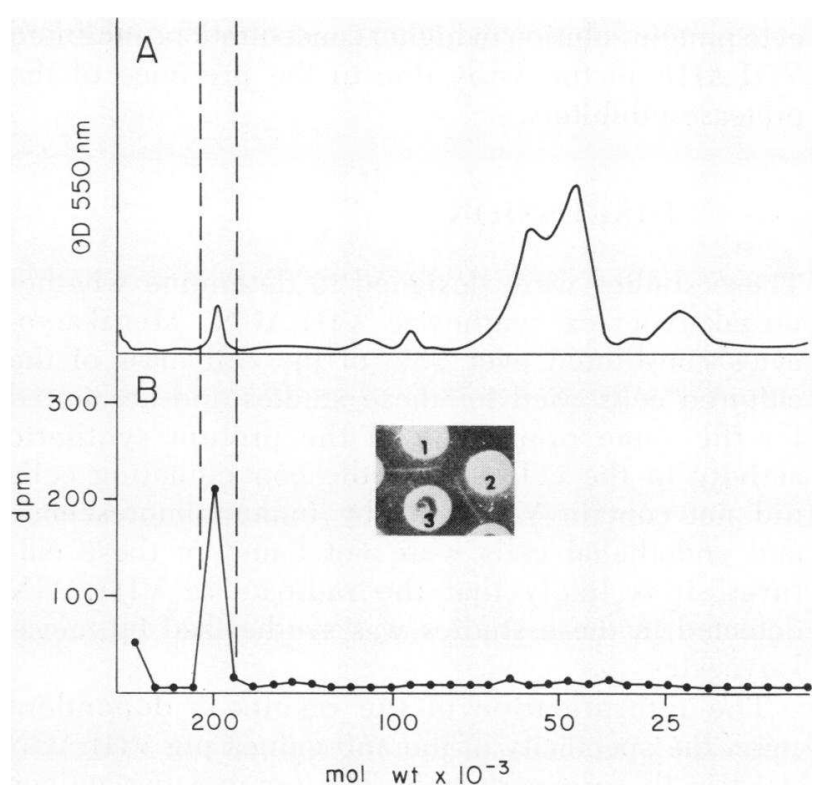

FIGURE 9 Immunoprecipitation of VIII:AGN synthesized by cultured guinea pig megakaryocytes (A). Densitometric scan of SDS polyacrylamide gels of semipurified guinea pig plasma VIII:AGN (14 $\mu \mathrm{g}$ on gel). (B) Distribution of radioactivity in solubilized washed immunoprecipitate formed on immunodiffusion between anti-guinea pig VIII: AGN and $\left[{ }^{3} \mathrm{H}\right]$ megakaryocyte protein. The vertical dashed lines enclose the guinea pig plasma VIII:AGN subunit region. (Inset) Immunodiffusion analysis in which $\left[{ }^{3} \mathrm{H}\right]$ megakaryocyte protein (1), and semipurified guinea pig plasma VIII:AGN (2), were reacted against anti-guinea pig VIII:AGN (3). Precipitin between wells 1 and 3 was used for study in panel $B$.

electrophoresis of the radioactive immunoprecipitate of the solubilized megakaryocyte protein (Fig. 9B) contained one radioactive band which co-migrated with the guinea pig VIII:AGN marker. Control studies were performed in which immunoprecipitates formed between anti-ceruloplasmin and $\left[{ }^{3} \mathrm{H}\right]$ megakaryocyte protein containing added nonradioactive ceruloplasmin were analyzed by SDS gel electrophoresis. No radioactive bands were detected in these control immunoprecipitates.

Assay of megakaryocyte solubilized protein for VIII:VWF and VIII:AHF. The megakaryocyte protein solution contained VIII:VWF as demonstrated by the support of ristocetin-induced aggregation of fixed washed normal human platelets in a plasmafree system. $50 \mu \mathrm{l}$ of megakaryocyte protein solution $(816 \mu \mathrm{g} / \mathrm{ml})$ was added to $350 \mu \mathrm{l}$ of fixed, washed platelets $(120,000 / \mu \mathrm{l})$. Aggregation occurred after the addition of ristocetin at a final concentration of $1 \mathrm{mg} / \mathrm{ml}$.

VIII:AHF was assayed in the megakaryocyte protein solution with a human Factor VIII-deficient plasma substrate. No procoagulant activity was detected at a dilution of 1:5 in PBS. The megakaryo- 
cyte protein solution in higher concentrations inhibited VIII:AHF in the assay due to the presence of the protease inhibitors.

\section{DISCUSSION}

These studies were designed to determine whether megakaryocytes synthesize VIII:AGN. Megakaryocytes constituted over $96 \%$ of the cell mass of the cultured cells used for these studies and accounted for the same proportion of the protein synthetic activity in the cells. Since the contaminating cells did not contain VIII:AGN by immunofluorescence and endothelial cells were not found in these cultures, it is likely that the radioactive VIII:AGN detected in these studies was synthesized by megakaryocytes.

The interpretation of the results is dependent upon the specificity of the anti-guinea pig VIII:AGN used in these experiments. The immunizing antigen (guinea pig VIII:AGN) was prepared from guinea pig plasma with a cross-reacting monospecific anti-human VIII:AGN which has been previously well characterized $(3,4,5,16)$. The anti-guinea pig VIII:AGN, when reacted against guinea pig plasma and semipurified guinea pig VIII:AGN, formed a single line of identity (Fig. 3). This same antibody also detected a single antigen in a preparation of partially purified human Factor VIII:AGN. The protein precipitated from guinea pig plasma by the anti-guinea pig VIII:AGN had the same subunit polypeptide molecular weight on SDS gels as the protein precipitated from guinea pig plasma by the cross-reacting monospecific anti-human VIII:AGN (Fig. 4). In addition, the anti-guinea pig VIII:AGN inhibited VIII:VWF of normal guinea pig plasma. It was important to prove that the antiserum did not react with cold insoluble globulin, a plasma protein that frequently contaminates Factor VIII preparations $(21,22)$. As previously noted, the rabbit anti-human VIII:AGN used to prepare the guinea pig VIII:AGN immunogen did not react with cold insoluble globulin (16). In addition, the protein precipitated from guinea pig plasma by the anti-guinea pig VIII:AGN had a mol wt of 200,000 on reduced gels and did not enter the gels in the unreduced state. Cold insoluble globulin in unreduced SDS gels moves into the gel with an apparent mol wt of 450,000 (22). The results demonstrate that the anti-guinea pig VIII:AGN used for these studies was monospecific.

It is of interest that the same antiserum did not inhibit the VIII procoagulant (VIII:AHF) activity of guinea pig plasma. This lack of anti-procoagulant activity is similar to our previous studies with an antiserum prepared against human endothelial cell VIII:AGN-VIII:VWF (4). That antiserum, which 920

R. Nachman, R. Levine, and E. A. Jaffe showed a strong precipitin against human plasma VIII:AGN and was a potent inhibitor of plasma VIII:VWF, was only a very weak inhibitor of plasma VIII:AHF. This dissociation has been previously observed with antisera from rabbits immunized with VIII:AGN derived from hemophilic plasma which contained no detectable VIII:AHF $(23,24)$. Variability of VIII:AHF inactivating properties of rabbit antisera has also been observed for animals immunized with different preparations of purified normal human plasma Factor VIII preparations (25).

The radioactive immunoprecipitin study (Fig. 9B) demonstrated synthesis of VIII:AGN by guinea pig megakaryocytes in culture. This study is similar to our previous studies demonstrating synthesis of VIII: AGN (and presumably VIII:VWF) by cultured human endothelial cells $(3,4,16)$. Human endothelial cell VIII:AGN and guinea pig megakaryocyte VIII:AGN have immunologic, functional, and biochemical similarities. They are immunologically similar or identical to their respective plasma VIII:AGN counterparts (Fig. 6 and [4]). Functionally, endothelial cell VIII:AGN and megakaryocyte VIII:AGN appear to be associated with VIII:VWF but lack VIII:AHF. Biochemically, both endothelial cell and megakaryocyte VIII:AGN are composed of polypeptide subunits of $200,000 \mathrm{~mol} w \mathrm{wt}$. The lack of VIII:AHF in the endothelial cell VIII:AGN appears to be an intrinsic property of the newly synthesized molecule rather than an artifact of the culture conditions (6). Studies have not yet been performed to determine whether this is also true for the VIII:AGN synthesized by the megakaryocyte in culture.

The biologic importance of megakaryocyte VIII: AGN (and VIII:VWF) synthesis remains to be determined. Studies from several laboratories clearly indicate that exogenous plasma VIII:AGN does not gain access to the platelet intracellular VIII:AGN pool $(7,10,11)$. It thus seems logical to assume that the intracellular platelet VIII:AGN is derived from megakaryocyte synthesis. Patients with aplastic anemia and markedly diminished megakaryocytes have normal plasma VIII:AGN levels. ${ }^{3}$ Thus, it appears that the endothelial cell is the source of plasma VIII:AGN and platelet surface membrane VIII:AGN while the megakaryocyte is the source of intracellular platelet granule VIII:AGN. It is at present unknown how these two separate VIII:AGN pools interact in normal hemostasis.

\section{ACKNOWLEDGMENTS}

This work was supported by grants from the National Institutes of Health, HL 18828 and HL-16271 (from the Specialized Center of Research), and the Arnold R. Krakower Foundation.

\footnotetext{
${ }^{3}$ Nachman, R., and E. Jaffe. Personal observations.
} 


\section{REFERENCES}

1. Bloom, A. L., J. C. Giddings, and C. J. Wilks. 1973. Factor VIII on the vascular intima: possible importance in hemostasis and thrombosis. Nat. New Biol. 241: 217-219.

2. Hoyer, L. W., R. P. de los Santos, and J. R. Hoyer. 1973. Antihemophilic factor antigen. Localization in endothelial cells by immunofluorescent microscopy. J. Clin. Invest. 52: 2737-2744.

3. Jaffe, E. A., L. W. Hoyer, and R. L. Nachman. 1973. Synthesis of antihemophilic factor antigen by cultured human endothelial cells. J. Clin. Invest. 51: 2757-2764

4. Jaffe, E. A., L. W. Hoyer, and R. L. Nachman. 1974. Synthesis of von Willebrand factor by cultured human endothelial cells. Proc. Natl. Acad. Sci. U. S. A. 71: 1906-1909.

5. Nachman, R. L., and E. A. Jaffe. 1975. Subcellular platelet factor VIII antigen and von Willebrand factor. J. Exp. Med. 141: 1101-1113.

6. Jaffe, E. A. 1977. Endothelial cells and the biology of factor VIII. N. Engl. J. Med. 296: 377-383.

7. Howard, M. A., D. C. Montgomery, and R. M. Hardisty. 1974. Factor-VIII-related antigen in platelets. Thromb. Res. 4: 617-624.

8. Coller, B. S., R. J. Hirschman, and H. R. Gralnick. 1975. Studies on the factor VIII/von Willebrand factor antigen on human platelets. Thromb. Res. 6: 469-480.

9. Piovella, F., E. Ascari, G. M. Sitar, G. D. Malamani, G. Cattaneo, E. Magliulo, and E. Storti. 1974. Immunofluorescent detection of factor VIII-related antigen in human platelets and megakaryocytes. Hemostasis. 3: 288295.

10. Green, D., and E. V. Potter. 1976. Platelet-bound ristocetin aggregation factor in normal subjects and patients with von Willebrand's disease. J. Lab. Clin. Med. 87: 976-986.

11. Manucci, P. M., and Z. M. Ruggeri. 1976. Pathogenesis of von Willebrand's disease. Lancet. I: 150-151.

12. Caen, J. P., A. T. Nurden, C. Jeanneau, H. Michel, G. Tobelem, S. Levy-Toledano, Y. Sultan, F. Valensi, and J. Bernard. 1976. Bernard-Soulier syndrome: a new platelet glycoprotein abnormality. Its relationship with platelet adhesion to subendothelium and with the factor
VIII von Willebrand protein. J. Lab. Clin. Med. 87: 586-596.

13. Evatt, B. C., and J. Levin. 1969. Measurement of thrombopoiesis in rabbits using 75 Selenomethionine. J. Clin. Invest. 48: 1615-1626.

14. Levine, R. F., and M. E. Fedorko. 1976. Isolation of intact megakaryocytes from guinea pig femoral marrow. J. Cell Biol. 69: 159-172.

15. Levine, R. F. 1977. In vitro culture of guinea pig megakaryocytes: Recovery, survival, maturation and morphologic changes. Blood. 50: 713-725.

16. Jaffe, E. A., and R. L. Nachman. 1975. Subunit structure of factor VIII antigen synthesized by cultured human endothelial cells. J. Clin. Invest. 56: 698-702.

17. Weber, K., and M. Osborn. 1969. The reliability of molecular weight determinations by dodecyl sulfatepolyacrylamide gel electrophoresis. J. Biol. Chem. 244: 4406-4412.

18. Breckenridge, R. T., and O. D. Ratnoff. 1962. Studies on the nature of the circulating anticoagulant directed against antihemophilic factor: with notes on assay for antihemophilic factor. Blood. 20: 137-149.

19. Allain, J. P., H. A. Cooper, R. H. Wagner, and K. M. Brinkhous. 1975. Platelets fixed with paraformaldehyde: a new reagent for assay of von Willebrand Factor and platelet aggregating factor. J. Lab. Clin. Med. 85: 318-328.

20. Harker, L. 1968. Megakaryocyte quantitation. J. Clin. Invest. 47: 452-457.

21. Cooper, H. A., R. H. Wagner, and M. W. Mosesson. 1974. The cold insoluble globulin of plasma and its relationship to factor VIII. J. Lab. Clin. Med. 84: 258-263.

22. Chen, A. B., and M. W. Mosesson. 1975. Covalent structure of the cold insoluble globulin of human plasma. Fed. Proc. 34: 259.

23. Kernoff, P. B. A. 1973. Affinity of factor VIII clotting activity for antigen detectable immunologically. Nat. New Biol. 244: 148-149.

24. Gralnick, H. R., B. S. Coller, and S. L. Marchesi. 1973. Immunological studies of factor VIII in hemophilia and von Willebrand's disease. Nat. New Biol. 244: 281-282.

25. Hougie, C., and R. Sargeant. 1973. Antigen/biologicalactivity rate for factor VIII. Lancet. I: 616 . 